\title{
What Can an Armchair Philosopher Do For a "Dirty-Hands" Engineer?
}

\author{
Pawel Garbacz
}

Received: 18 May 2010/ Accepted: 20 September 2010/Published online: 28 December 2010

(C) The Author(s) 2010. This article is published with open access at Springerlink.com

\begin{abstract}
The paper relates the basic ontological categories defined by Roman Ingarden to an engineering model of function known by the name of Functional Basis. The intended aim of this exercise in applied philosophy is to make this model more consistent and outline some possible extensions thereof.
\end{abstract}

Keywords Function · Artefact · Ontology

The current philosophical debate over the notion of artefactual function tends to overlook the engineering insight. It is a rule rather than an exception that a philosopher focuses his or her mind only over the every-day examples of functions, like that of covering the body, which is performed (or ascribed to) a dress. Similarly, engineers tend to ignore the philosophical rambling even if its scope overlaps the domain of their interests. On the one hand, this mutual ignorance is justified by the different methodological principles of these scientific enterprises. On the other hand, the deficit of communication between philosophy and engineering is not beneficial for either discipline. In this paper I want to show a conceptual ground on which philosophers and engineers may cooperate for the benefit of both enterprises.

Being flooded by the enormous amount of data related to their professional activities, engineers search for reusable and sharable computer systems that would store the results of these activities. One of the problems they face during this pursuit is the variety of engineering representations of technical functions. A number of standarisation efforts were undertaken to reconcile the differences in engineering functional representations. Usually these standards may be covered by the umbrella

P. Garbacz (ه)

John Paul II Catholic University of Lublin, Lublin, Poland

e-mail: garbacz@kul.pl 
term of engineering ontology (see e.g. Chandrasekaran et al. 1999), but it must be remembered that the standards differ significantly in their logical structure. From the point of view of a philosopher, these efforts are particularly interesting because they usually involve the general considerations that the philosopher finds familiar. This paper deals with the general question of the adequate ontological category of artefactual function. What are (technical) functions?

The question is of interest for a philosopher. But it might be argued that the ontological categorisation of technical functions is relevant also for an engineer when the latter aims at a standard for functional representation. Without the watertight understanding of technical functions we may end up in an inadequate model that is not precise enough to reach the standarisation goals. The need for the clear conceptualisation of artefactual function is alleviated by the known discrepancies between different engineering models.

In order to tackle the issue of ontological categorisation, I will pick up one engineering model of functions and one ontological theory and try to match the engineering notion of function from the former with one of the ontological categories from the latter. The engineering model of my choice will be the Functional Basis repository developed within the Design Engineering Lab at the Missouri University of Science and Technology and the ontological system will be the theory constructed by the Polish philosopher Roman Ingarden.

The choice of the Functional Basis repository is made on the basis of its relative success in modelling functions in the domain of mechanical engineering. ${ }^{1}$ The choice of Ingarden's ontology may be justified by its epistemological values, in particular by its flexibility to accommodate the engineering viewpoint embedded in the Functional Basis approach.

\section{Functions as Represented in Functional Basis Repository}

The Functional Basis research grew out of the needs to describe and compare products functionally and to create a formal function representation that would advance design methods and lead to sharable and reusable representations.

The origin of this approach can be located in the foundational work of Pahl and Beitz (1996); current research centres on a framework proposed by Stone, Wood, and others (cf. Stone and Wood 2000).

Pahl and Beitz define a function as a relation between an input and an output of a technical system (under a specific goal). Each technical function is claimed to be derived from a flow (Pahl and Beitz 1996, p. 31). A flow is either a conversion of material (e.g., a chunk of clay being converted into a vase), a conversion of energy (e.g., electrical energy being converted into heat), or a conversion of signal (e.g., a safety buzz indicating the high pressure of a vapour). Pahl and Beitz do not spell out

\footnotetext{
1 Other engineering construals of the notion of function are presented in Chandrasekaran and Josephson (2000), Chittaro and Kumar (1998), Deng (2002), Gero (1990), Keuneke (1991), Lind (1994), Rosenman and Gero (1998), among others. Erden et al. (2008) is a recent survey paper in this domain.
} 
what it means that functions are derived from flows. But in their definitions and examples they presuppose that any function boils down to a flow, for instance, when they refer to a function denoted by the expression "transfer torque", which clearly is a flow of torque. Pahl and Beitz consider five types of flow conversions:

- to channel,

- to connect,

- to vary,

- to change,

- to store.

Together with their distinction between flows of material, energy and signal, one arrives at the taxonomy of 15 basic functions, which contains such functions as "to channel material" or "to store signal".

By taking functions as conversions of flows of materials, energies and signals, functions seem to have to comply with physical conservation laws for such flows. The conversion of a signal flow representing a small amount of energy, into a large electromagnetic energy flow, seems not to be a function in Pahl and Beitz' methodology.

A more recent research project that originates from this work is the (Reconciled) Functional Basis (RFB, from now on) that aims at establishing a standard for engineering functional models (see, e.g., (Hirtz et al. 2001)). RFB combines two previous standards: the National Institute of Science and Technology taxonomy of functions (Szykman et al. 1999) and the older versions of the Functional Basis (developed in Little et al. 1997 and Stone et al. 1998).

\subsection{Functional Basis Model}

The RFB developers provide the detailed motivation for a standard in functional modelling by pointing out to the areas of product design where such models are likely to increase the effectiveness of engineering efforts:

1. exploration of product architecture possibilities,

2. storage, retrieval and sharing design information,

3. comparison of product functionalities,

4. (automated or semi-automated) design concept generation,

5. objective measures of product benchmarks (Stone and Wood 2000, p. 359).

For us it is important to note that the need for clear and consistent definitions of functional terms is emphasised in this context.

RFB follows the classic paradigm of Pahl and Beitz in defining artifact functions in terms of flows. The RFB classification of flows refines Pahl and Beitz' taxonomy: the most general division of flows in RFB distinguishes between material, energy, and signal flows, which are further divided at the lower levels of the classification. Nonetheless, RFB modifies the meaning of the term "flow" since here "flow" does not mean "a process of flowing" (e.g., removing debris), but "a thing that flows" (e.g., debris). Thus, flows are no longer conversions of matter, energy, and signal, 
but chunks of matter, energy, and signal being converted. ${ }^{2}$ This shift in meaning is, to be sure, justifiable since it is hard to see how one might differentiate between a process of flowing and a function given the conception of Pahl and Beitz.

In fact the RFB model hinges upon two classifications: the classification of flows and the classification of conversions of flows. By means of those classifications the RFB developers have identified 50 (types of) flows and 36 (types of) conversions which are claimed to be sufficient for the adequate functional representation of any technical device (Hirtz et al. 2001). Figure 1 represents the functional structure of an electrical screwdriver.

The RFB model of device functions boils down to a three-level classification. Each node in this classification is accompanied by a definition (in natural language), example(s), and a set of synonymous names. All functions are divided in a first layer into eight primary kinds. Then, some primary functions are divided into secondary functions, and some of these secondary functions are in turn divided into kinds of tertiary functions. The whole taxonomy is depicted in Table 1. A few examples and what RFB calls the definitions of functions are given in Tables 2 and 3.

What are RFB functions? The developers of RFB warn us that they employ three notions of function (Stone and Wood 2000, pp. 359-360):

- A product function is a general input/output relationship of a product having the purpose of performing an overall task, typically stated in verb-object form.

- A subfunction is a description (sic!) of part of a product function, stated in verbobject form. Subfunctions are claimed to represent the more elementary tasks of the product.

- A function is a description (sic!) of an operation to be performed by a device of artefact, expressed as the active verb of the subfunctions.

In order to avoid some awkwardness of this terminology ${ }^{3}$, I will use the terms "product functions", "basic functions", and "functional operations" to refer to the respective types of functions defined by these definitions. ${ }^{4}$

Comparing them against the above taxonomies, one might probably say that

- The relation between the input and the output of an atomiser is a product function of this atomiser.

- The sentence (or the corresponding proposition?) "A surge protector conditions electrical energy by excluding spikes and noise from the energy path" is (sic!) a basic function of a power supply in my computer.

- The verb "to condition" is (sic!) a functional operation of this surge protector.

\footnotetext{
2 More precisely speaking, in some papers, e.g., in Stone and Wood (2000), this term is sometimes used in both meanings, but the RFB taxonomy of flows is based on the latter sense.

3 For example, the RFB model implies that it is not the case that each product function is a function.

4 Alternatively, one could use the term "thick functions" instead of "basic functions" and the term "thin functions" instead of "functional operations".
} 


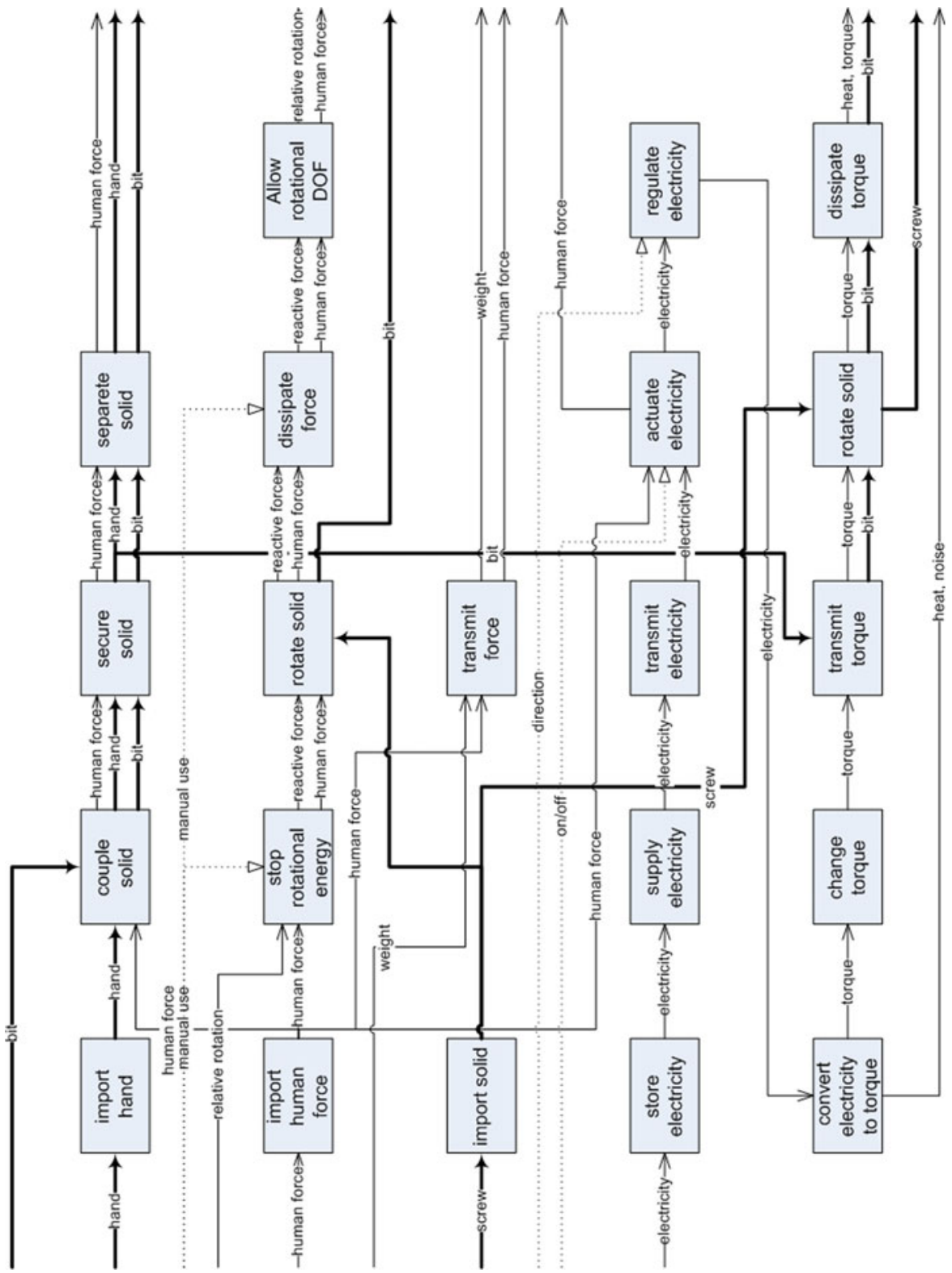

Fig. 1 Functional decomposition of electrical screwdriver (Stone and Wood 2000, p. 364)

\subsection{Functional Basis and Conceptual Clarity}

As we can see, the RFB definitions are far from being clear. First, the RFB authors do not seem to put too much emphasis on the distinction between a description and 
Table 1 RFB taxonomy of functional operations

\begin{tabular}{|c|c|c|}
\hline Primary functions & Secondary functions & Tertiary functions \\
\hline \multirow[t]{4}{*}{ Branch } & Distribute & \\
\hline & Separate & Divide \\
\hline & & Extract \\
\hline & & Remove \\
\hline \multirow[t]{7}{*}{ Channel } & Import & \\
\hline & Export & \\
\hline & Transfer & Transport \\
\hline & & Transmit \\
\hline & Guide & Translate \\
\hline & & Rotate \\
\hline & & $\begin{array}{l}\text { Allow degree(s) } \\
\text { of freedom }\end{array}$ \\
\hline \multirow[t]{3}{*}{ Connect } & Mix & \\
\hline & Couple & Join \\
\hline & & Link \\
\hline \multirow[t]{9}{*}{ Control Magnitude } & Actuate & \\
\hline & Regulate & Increase \\
\hline & & Decrease \\
\hline & Change & Increment \\
\hline & & Decrement \\
\hline & & Shape \\
\hline & & Condition \\
\hline & Stop & Prevent \\
\hline & & Inhibit \\
\hline \multicolumn{3}{|l|}{ Convert } \\
\hline \multirow[t]{3}{*}{ Provision } & Supply & \\
\hline & Store & Contain \\
\hline & & Collect \\
\hline \multirow[t]{8}{*}{ Signal } & Sense & Detect \\
\hline & & Measure \\
\hline & Indicate & Track \\
\hline & & Display \\
\hline & Process & \\
\hline & Stabilise & \\
\hline & Secure & \\
\hline & Position & \\
\hline
\end{tabular}

the thing being described. The product functions, as defined above, belong to the real world as its components, while basic functions and functional operations are just descriptions. A more serious objection is that the RFB definitions do not determine their ontological referents in a satisfactory manner. For example, if a 
Table 2 Definitions of RFB conversions of flows-sample

\begin{tabular}{ll}
\hline Function & Definition \\
\hline Distribute & To cause a material or energy to break up \\
Translate & To fix the movement of a material (by a device) into one linear direction \\
Condition & To render an energy appropriate for the desired use \\
Display & To show a visual effect \\
\hline
\end{tabular}

Table 3 Examples of RFB conversions of flows-sample

\begin{tabular}{ll}
\hline Function & Example \\
\hline $\begin{array}{l}\text { Distribute } \\
\text { Translate }\end{array}$ & $\begin{array}{l}\text { In an assembly line, a conveyor belt translates partially completed products from one } \\
\text { assembly station to another }\end{array}$ \\
$\begin{array}{ll}\text { Condition } & \text { A surge protector conditions electrical energy by excluding spikes and noise from the energy } \\
\text { path } \\
\text { Display }\end{array}$ & The face and needle of an air pressure gage display the status of the pressure vessel
\end{tabular}

product function is just a relationship, how can it be composed out of basic functions described by the verb-object form?

Although this lack of ontological transparency does not seem to be something of a worry to an engineer, it might affect the very project of constructing standards for functional models. If our basic principles are not clear enough, one cannot expect that the resulting representation will exhibit the required level of conceptual transparency. This affects the RFB approach itself. Sometimes it follows its own definitions separating basic functions, which are represented by the verb-object form, from functional operations. In other cases the RFB specification treats basic functions as functional operations. The most imminent example is the function "Allow degrees of freedom", which combines a functional operation and a flow, but is mentioned as one of functional operations and not a basic function. But also other functional operations seem to be "contaminated", so to speak, by flows. Consider for example the functional operation "Display". The RFB "definition" says: Display. To show a visual effect, where the visual effect is interpreted here as a signal. Thus, effectively, this functional operation is a basic function because it is described by the verb-object structure. Still, it is classified as a functional operation.

Despite the above problems, it is possible to give a consistent ontological interpretation for RFB notion(s) of artefactual functions. The ontological theory that serves us as the basis for interpretation is Roman Ingarden's ontology. It seems to me that as a result, the conceptual clarity of the RFB functional model will be increased. And this is what engineering functional models are all about.

The doubt may arise whether the categories of Ingarden's ontology are conceptually apt to fit the engineering framework. If the latter ontology is 
sufficiently adequate, it should cover also the engineering domain, in which case it should provide with the suitable categories to capture the RFB model. However, it is beyond the scope of the present paper to discuss this issue, so the proof of concept of the methodology I adopt boils down to the proof of pudding: if the conceptual mapping described below is robust, its methodology is proven sound.

\section{Ingarden's Ontological Categories}

Due to the scope and intricacy of Ingarden's philosophy, it is impossible to describe even the main ideas of his system in a satisfactory detail. Thus, the remarks that follow are to be treated as a kind of roadmap that is to link his ontology with the universe of engineering. The reader unfamiliar with Ingarden's contribution should consider few available reference works, e.g. Gregor (1994) or Chrudzimski (2005).

Ingarden starts with a three-dimensional category scheme that is defined by three distinct features of being: formal structure, material content, and existential aspect. Each of these features corresponds to one part of ontology: formal, material, and existential ontology. Since most of Ingarden's considerations on material ontology are not relevant for the present purposes, I will neglect them here referring mainly to Ingarden's opus magnum (Ingarden 1964-1965), which presents his existential and formal ontological considerations.

\subsection{Existential Ontology}

Ingarden believed that ontology, as the study of the content of ideas, does not commit us to the existence of any particular object or class of objects. The ontological investigation is located in the domain of what is possible and what is necessary without any prejudice as to what actually exists (cf. Ingarden 1964-1965, vol. 1, chap. II). So, for example, when he claims that processes are real objects that exist in time in such and such way, he does not claim that any process actually exists. He only says that if any process existed, then it would have to be a real object existing in time in that and that way.

The existential ontology defines four basic ways (or modes) of being by clustering four oppositions of the so-called moments of existence (or existential moments). This is how Peter Simons explains Ingarden's notion of existential moment (Simons 2005, p. 41):

Existential moments are repeatable features that occur across different modes of being: they are moments because they are not themselves independent modes of being, and they are existential because they determine modes of being. Existential moments come in families of two or more contrary members, such that no mode of being has more than one member from such a family determining it, and each mode of being is determined by a unique combination of existential moments from various of these families.

Ingarden mentions four general pairs of existential moments (cf. Ingarden 1964-1965, vol. 1, chap. III): 
1. originality versus derivativity:

- An entity is original (seinsursprünglich) if it cannot be created by any other entity. ${ }^{5}$

- An entity is derivative (seinsabgeleitet) if it can be created by some entity.

2. autonomy versus heteronomy:

- An entity is autonomous (seinsautonom) if it has its ontic fundament in itself or, in other words, is immanently determined.

- A heteronomous entity (seinsheteronom) has its ontic fundament determined by something outside itself or, in other words, has its being in and only thanks to something outside itself.

- The superficiality of this exposition of Ingarden's philosophy is most acute in the case of heteronomy. Roughly speaking, the category of heteronomous entities comprises various types of works of art with writers, composers, painters, etc. as their ontic fundaments. Amie Thomasson has shown recently that it can also cover all socio-cultural objects such as churches, flags, and laws (Thomasson 2005). Besides intentional objects, Ingarden mentions also intentional states of affairs, which are created when an agent entertains some kind of belief. I will use the term "intentional entities" to cover all kinds of intentional beings.

- Among heteronomous entities Ingarden sets apart purely intentional entities whose existence is entirely determined by their creators. Sherlock Holmes might be an example at stake. ${ }^{6}$

- Some purely intentional entities represent other entities, mainly the real ones. To be more specific, some purely intentional entities are created with the intention of representing other entities, which intention might be satisfied or not. For example, when I believe that Elvis Presley is alive, I, by entertaining this belief, create an intentional entity whose role is to represent certain real state of affairs, even if this role is not fulfilled, i.e. even if it does not represent any such state of affairs. Given the peculiar nature of ontic heteronomy, any adequate ontological representation of an intentional object should include the representation of the ontic fundament of this object.

3. self-sufficiency versus non-selfsufficiency:

- An entity is self-sufficient (seinsselbständig) if it can exist on its own without being part of a larger whole, e.g., John, who can exists without being part of a larger whole,

\footnotetext{
${ }^{5}$ I uphold in this paper Ingarden's distinction between entities and objects. The former notion covers the whole domain of being, while the latter is restricted to entities endowed with properties, i.e. to Ingarden's individual objects.

${ }^{6}$ Let me just note in passing that by the lights of Ingarden's ontology Sherlock Holmes is created not only by Arthur C. Doyle, but also by any reader of his books. Here the nature of the relation of ontological dependency is quite intricate and I will not discuss it.
} 
- An entity is non-selfsufficient (seinsunselbständig) if it can exist only in a whole with something else, e.g., the weight of John, which cannot exist without existing in John.

4. independence versus dependence:

- If a self-sufficient entity does not requires for its existence that any other self-sufficient entity should exist, then the former entity is independent (seinsunabhängig), e.g., John's eyes, which cannot exist without John himself.

- If a self-sufficient entity requires for its existence that another self-sufficient entity should exist, then the former entity is dependent (seinsabhängig), e.g., John. $^{7}$

These four types cover the whole domain of being, including atemporal entities. If we focus on temporality, we can distinguish three additional oppositions:

1. being fissurated versus being non-fissurated:

- An entity is fissurated if its actuality is constrained to a moment in time; in other words, it is actual only at a certain moment.

- An entity is non-fissurated if its actuality spans over a time period.

2. persistence versus fragility:

- An entity is persistent if it is within its dispositions to overcome the destructive flow of time,

- An entity is fragile if it perishes in the course of time.

3. and finally, post-actuality (past entities) versus actuality (present entities) versus empirical possibility (future entities).

Combining these existential moments, Ingarden gets 15 solutions, which he groups into four spheres: absolute, ideal, real, and intentional. The sphere of real entities is further divided into eight real ways of existence (cf. Ingarden 1964-1965, vol. 1, chap. VI). We can classify them in two dimensions. One is given by the distinction between endurants, processes, and events. ${ }^{8}$ The other dimension is related to the temporal location of a given real entity: past, actuality, future. I will focus only on actual entities.

An (actual) endurant is an entity that is autonomous, derivative, self-sufficient, and independent.

A (actual) process is autonomous, derivative, self-sufficient, and dependent on a endurant or a group of endurants.

An (actual) event is autonomous, derivative, and non-selfsufficient being part of a certain process.

\footnotetext{
7 The English terminology is taken from Simons (1986, 2005). The entry on Roman Ingarden in the Routledge Encyclopedia of Philosophy uses a slightly different terminology.

${ }^{8}$ For Ingarden, an event is either an end point or a starting point of a process (or a point at which two processes intersect). Therefore, events, as opposed to processes, are instantaneous.
} 
Let me just mention in passing that some combinations of existential moments are claimed by Ingarden to be inconsistent. For example, he argues that no object can bear the moment of non-selfsufficiency and the moment of dependency.

\subsection{Formal Ontology}

This part of Ingarden's system does not hinge upon such nicely carved distinctions. Although no exhaustive list is provided, we can find the following formalontological categories of being (cf. Ingarden 1964-1965, vol. 2, passim):

- individual objects:

- primary individual objects,

- higher-order individual objects.

- states of affairs (Sachverhalten),

- relations,

- ideas,

- ideal qualities (ideale Qualitäten),

- domains of objects.

The principle of this distinction is the form of the respective objects, i.e. the way in which the qualitative, i.e. "material", aspects of these objects stand. This is how Daniel von Wachter describes this distinction (von Wachter 2005, pp. 67-68):

An entity's matter is that which is purely qualitative in it. The entity's form is that "in which the matter stands"; it is that which gives the matter its place in the ontological structure of the entity. Ingarden calls it the how of the object's attributes, implying that it gives the matter its form.

Still, the above list is not exhaustive, at least Ingarden never claimed that the above formal ontological categories exhaust the whole domain of being.

Below I briefly characterise those formal-ontological categories that will be used in Sect. 4.

From the point of view of Ingarden's formal ontology, an individual object is a subject (i.e. bearer) of properties; if it is a mereological sum of other individual objects, then it is qualified as higher-order. The category of states of affairs comprises a family of slightly heterogonous subcategories. If an individual object has a certain property, e.g. John is obese, then the ontological conglomerate composed out of John and his obeseness, is a state of affairs. Similarly, when John runs, then the compound of John and the process of his running is also a state of affairs. Ingarden mentions also other subcategories of states of affairs, e.g. those that correspond to conditionals. Ideas are separated from other formal categories by their two-sided formal constitution: they have their own ontological structure and content. The structure of an idea is this formal-ontological aspect that determines it qua idea. Ingarden is not entirely clear what this claim of his actually means, but he mentions the immutability, atemporality, generality, and two-sided constitution as the definitional features of ideas. The content of an idea is this formal-ontological aspect due to which the idea refers or mirrors some other entity. We can name the 
relationship between the ideas and the entities that they are ideas of using the more modern term of "instantiation". So, when $x$ is an idea of $y$, we can say that $y$ is an instantiation of $x$ or that $x$ instantiates $y$. Ingarden observes that the content of any idea consists of constant and variable elements. Consider the idea of a square. This idea instantiates particular squares. The constant elements in its content are being a plane polygon, having four sides, and having all sides equal. The variable element in this content is the length of the side of the square. Having both constants and variables, the idea of the square is, so to speak, ontologically apt to instantiate particular squares of different sizes. It is worth to note that Ingarden insists that any entity has its own idea. Thus, there is an idea of individual objects, states of affairs, and even the idea of ideas. ${ }^{9}$

How to fit the RFB functions into such lofty ontological framework?

\section{Ingarden's Formal Ontology and Formal Ontologies in KR/AI}

Before applying Ingarden's categories to RFB let me briefly digress on the question of comparison between these categories and the categories of some of the most prominent formal ontologies built within the context of Knowledge Representation and Artificial Intelligence. Although the detailed and well-motivated comparison is far beyond the scope of this paper, I collected in Table 4 some rough and ready correspondences taking into account three examples of the latter:

- BFo (Basic Formal Ontology—see http://www.ifomis.org/bfo);

- GFo (General Formal Ontology—see http://www.onto-med.de/en/theories/gfo);

- DOLCE (Descrptive Ontology for Linguistic and Cognitive Resources-see http://www.loa-cnr.it/DOLCE.html).

When there is no correspondence, the "-" is displayed. In some cases the correspondence holds between a category of Ingarden and some set-theoretical combination of categories from one of those ontologies. Then the standard settheoretical symbols are used: " $\cap ", " \cup ", " \backslash "$.

It needs to emphasised however that the phenomenological method used by Ingarden makes is virtually impossible to compare his categories to the extensional notions of the aforementioned formal ontologies provided that one aspires to grasp all conceptual details of the latter.

\section{Ontological Categorisation of Function}

First, let me draw the reader's attention to the fact that Ingarden's distinction between the real and the ideal sphere of being allows us to explicate the difference

\footnotetext{
9 Incidentally, let me observe that one should not confuse Ingarden's ideas with ideal qualities. An ideal quality (e.g. redness, sadness, etc.) is an entity that can be exemplified either as a component of the content of an idea or as a existential, formal or material aspect of a real entity. So, in a sense, ideas are composed out of ideal qualities. One of the differences between ideas and ideal qualities is that only the former within their two-sided constitution are determined by the variable element in their contents.
} 
Table 4 Ingarden's formal ontology versus KR/AI formal ontologies

\begin{tabular}{llll}
\hline $\begin{array}{l}\text { Ingarden's formal } \\
\text { ontology }\end{array}$ & BFO & GFO & DOLCE \\
\hline primary individual objects & $\begin{array}{l}\text { mereologically atomic } \\
\text { entities }\end{array}$ & $\begin{array}{l}\text { mereologically atomic } \\
\text { objects }\end{array}$ & $\begin{array}{l}\text { mereologically atomic } \\
\text { endurants } \cup \text { perdurants }\end{array}$ \\
higher-order individual & mereologically complex & mereologically complex \\
objects & entities & mereologically complex \\
states of affairs & - & facts $\cup$ situations & - \\
relations & - & relators & - \\
ideas & - & - & - \\
ideal qualities & - & property universals & abstract particulars \\
domains of objects & - & - & - \\
\hline
\end{tabular}

between function-tokens and function-types. The way in which RFB describes engineering function does not always make it clear whether we deal with the former or the latter. That is to say, the RFB representation of device functions does not specify whether these functions are particular occurrences or general patterns. Be it as it may, Ingarden's ontology can accommodate both kinds: function-tokens are located in the sphere of real entities, while function types exist in the realm of ideas. So we can have tokens of product functions, basic functions and functional operations, which are real entities instantiated by the types of product functions, basic functions, and functional operations. The former exist in time, while the latter are atemporal.

Secondly, the existential moment of heteronomy allows us to fill one gap in the modelling assumptions that support RFB. Ookubo et al. (2007) points out that the RFB approach does not explicitly distinguish between functions and behaviours, which distinction is taken for granted in other functional models. In particular, the intentions of the designer and/or the teleological context are not explicitly stated.

Ingarden's notion of intentional objects may be of avail here. Besides separating function types from function tokens, we might also wish to distinguish between intended and realised functions. The principle of distinction is the opposition between ontic autonomy and heteronomy. A realised function would be an autonomous entity that exists either in the domain of real beings, if it is a function token, or in the domain of ideal beings, if it is a function type. Thus, when the surge protector in the power supply of my computer actually conditions electrical energy by excluding spikes and noise from the energy path, this state of affairs is a realised function. An intended function (i.e., either a function token or a function type) is an intentional entity that represents a realised function. When an engineer in the conceptual phase of his or her design allocates a certain function to an artefact that does not even exist at that time, then we can say that he or she creates an intended function that will represent a respective realised function when the artefact is finally manufactured (provided that the design he or she obtains is feasible). Thus, when the designer of my computer decided that there is a need to condition electrical 
energy by means of the surge protector, he or she created an intended function, which, at that time, existed heteronomously.

Combing the two distinctions, we get

1. realised function types, which are categorised as Ingarden's ideas,

2. realised function tokens, which are categorised as Ingarden's real entities,

3. intended function types, which are categorised as those intentional entities that represent ideas,

4. intended function tokens, which are categorised as those intentional entities that represent real entities.

Thirdly, we can locate the RFB product functions, basic functions and functional operations within the above sketched ontological categories.

Both the general definitions and the specific examples we find in RFB imply that functional operations are Ingarden's processes. To be more precise, functional operations are either processes or events. For example, the verb "to actuate" seems to denote instantaneous processes, which fall under Ingarden's category of events.

On the other hand, basic functions seem to fall under the category of states of affairs. If basic functions are adequately represented by the verb-object form, e.g. "to transport sand", then this implies that they involve two kinds of entities. One kind is denoted by the verb and the other is denoted by the object. Thus, we have the process of transporting and sand that is being transported. It should be obvious that among the categories listed above it is the category of states of affairs that is the most suitable candidate to cover such ontological conglomerates. The function that is represented by the verb-object structure "to transport sand" is then the state of affairs in which one individual object, namely sand, participates in a process due to which it changes its location.

One of the problems that this categorisation implies is the gap between Ingarden's rather abstract notions and the down-to-earth concepts used by engineers. The above categorisation assumes that we can stitch the engineering notions under the ontological categories in a consistent and non-arbitrary way, but at first sight this "stitching" is not straightforward. For example, it is by no means obvious that the three basic types of flows in RFB approach, i.e. matter, energy, and information, are individual objects in the sense of Ingarden: is it plausible to categorise sand as an individual object? What about energy and signal?

One should bear in mind the distinction between tokens and types, which distinction we are able to reconstruct in Ingarden's system. So we can classify engineering entities either as tokens or as types. Namely, we are able to distinguish between a particular heap of sand and the idea of sand. When an engineer speaks about sand, we can interpret his or her talk either as being about a particular individual object, i.e. about this heap of sand, or as being about the idea of sand that instantiates all heaps of sands, which are individual objects.

If the verb-object structure is interpreted as denoting a function token, then we can categorise the ontological reality this structure represents saying that a particular heap of sand, which is categorised as an individual object, participates in a particular process. On the other hand, when the verb-object structure is interpreted as denoting a function type, then we can say that: 
Table 5 Ontological categorisation of RFB functional concepts

\begin{tabular}{|c|c|c|c|}
\hline RFB categories & $\begin{array}{l}\text { Intended/ } \\
\text { realised } \\
\text { distinction }\end{array}$ & $\begin{array}{l}\text { Type/ } \\
\text { token } \\
\text { distinction }\end{array}$ & Ingarden's categories \\
\hline \multirow[t]{2}{*}{$\begin{array}{l}\text { functional } \\
\text { operation }\end{array}$} & intended & $\begin{array}{l}\text { type } \\
\text { token }\end{array}$ & $\begin{array}{l}\text { intentional entity representing ideas of processes/events } \\
\text { intentional entity representing real processes/events }\end{array}$ \\
\hline & realised & $\begin{array}{l}\text { type } \\
\text { token }\end{array}$ & $\begin{array}{l}\text { ideas of processes/events } \\
\text { processes/events }\end{array}$ \\
\hline \multirow[t]{2}{*}{ basic function } & intended & $\begin{array}{l}\text { type } \\
\text { token }\end{array}$ & $\begin{array}{l}\text { intentional entity representing ideas of states of affairs } \\
\text { intentional entity representing real states of affairs }\end{array}$ \\
\hline & realised & $\begin{array}{l}\text { type } \\
\text { token }\end{array}$ & $\begin{array}{l}\text { ideas of states of affairs } \\
\text { states of affairs }\end{array}$ \\
\hline \multirow[t]{2}{*}{ product function } & intended & $\begin{array}{l}\text { type } \\
\text { token }\end{array}$ & $\begin{array}{l}\text { intentional entity representing ideas of states of affairs } \\
\text { intentional entity representing real states of affairs }\end{array}$ \\
\hline & realised & $\begin{array}{l}\text { type } \\
\text { token }\end{array}$ & $\begin{array}{l}\text { ideas of states of affairs } \\
\text { states of affairs }\end{array}$ \\
\hline
\end{tabular}

- the noun "sand" denotes the idea of sand, which instantiates particular heaps of sand,

- the verb "transport" denotes the idea of transportation, which instantiates particular processes,

- the whole verb-object structure "to transport sand" denotes the idea of a certain state of affairs in which sand is being transported, which idea instantiates particular (real) states of affairs in which particular heaps of sand are being transported.

Ingarden's notion of individual object is broad enough to cover all engineering kinds of material, energy, or information. Any real object that is a bearer of properties belongs to this category. So, if engineers ascribe any properties to sand (or to electrical energy or to digital signals), then we are justified in categorising it as an individual object.

As for product functions, although they are defined in a different way from basic functions, they fall under the category of states of affairs as well. First, they are always represented by the standard verb-object form. Secondly, they are composed out of basic functions that are categorised here as states of affairs. Consequently, the product functions and the basic functions belong to the same ontological category. The difference therebetween is that the former are not parts of other functions while the latter always are.

The two binary distinctions I suggested earlier imply that we can "split" the RFB product functions, basic functions, and functional operations into tokens and types, and orthogonally, into intended and realised functions. That is to say, the initial RFB tertiary partition may be refined to 12 kinds of functional categories-see Table 5 .

Finally, besides allocating engineering categories to the well-defined ontological scheme, the above categorisation may give rise to a number of more specific 
modelling clues that may extend the current ontological perspective of RFB. Here is a sample of such clues:

- Being categorised as Ingarden's ideas, all RFB function types may need to be represented by their variable and constant elements. Thus, instead of just naming a given function, the RFB repository may make it explicit which entities are constant and which change when this functions is successfully executed.

- Because intended functions are heteronomous entities, we may need to describe the agent(s) who is responsible for their creation. This relativisation to agents is explicit in other models, e.g. in the Functional Representation approach (Chandrasekaran and Josephson 2000).

- The ontological distinction between processes and states of affairs recommends separating basic functions from functional operations. The taxonomy in Table 1 needs to be disambiguated between its processual and "state-of-affairal" interpretation.

- Provided that flows are categorised as individual objects, we may need to represent them by means of (lists of) properties. Again, instead of just naming a given flow, the RFB repository may make it explicit which properties an object should have so that it could be classified as an instance of this flow.

- The RFB functional operations may be further divided into Ingarden's events and processes. When a functional operation is an event, we may need to specify which process the functional operation is part of.

\section{Conclusions}

The above philosophical exercise shows, I hope, that there are at least two things that an armchair philosopher can do for a hands-on engineer. First, the philosopher may tidy up the language and conceptual schema by means of which the engineer describes his or her work. In particular, he might recommend to the engineer a number of distinctions that might reduce the threat of ambiguity. (A bunch of fancy philosophical terms is also included in this package.) Secondly, the philosopher may suggest how to extend or develop engineering models by revealing the consequences of the ontological interpretation of those models.

Not much, but you cannot expect to get much more from someone who does not like getting his or her hands dirty.

Open Access This article is distributed under the terms of the Creative Commons Attribution Noncommercial License which permits any noncommercial use, distribution, and reproduction in any medium, provided the original author(s) and source are credited.

\section{References}

Chandrasekaran B, Josephson JR (2000) Function in device representation. Eng Comput 16(3/4):162-177

Chandrasekaran B, Josephson JR, Benjamins VR (1999) What are ontologies, and why do we need them?. IEEE Intell Syst 14(1):20-26 
Chittaro L, Kumar AN (1998) Reasoning about function and its applications to engineering. Artif Intell Eng 12:331-336

Chrudzimski A (ed) (2005) Existence, culture, and persons. The ontology of Roman Ingarden. Ontos verlag

Deng YM (2002) Function and behavior representation in conceptual mechanical design. Artif Intell Eng Des Anal Manuf 16:343-362

Erden MS, Komoto H, van Beek TJ, Amelio V, Echavarria E, Tomiyama T (2008) Review of function modeling: approaches and applications. Artif Intell Eng Des Anal Manuf 22:147-169

Gero JS (1990) Design prototypes: a knowledge representation schema for design. AI Magazine 11:26-36

Gregor H (1994) Über Existenz: Die Ontologie Roman Ingardens. Kluwer, Dordrecht

Hirtz J, Stone RB, McAdams DA, Szykman S, Wood K (2001) A functional basis for engineering design: reconciling and evolving previous efforts. Res Eng Des 13:65-82

Ingarden R (1964-1965) Der Streit um die Existenz der Welt, vol 1-2. Max Niemeyer, Tubingen

Keuneke AM (1991) Device representation: the significance of functional knowledge. IEEE Expert 24:22-25

Lind M (1994) Modeling goals and functions of complex plants. Artif Intell 8:259-283

Little A, Wood K, McAdams D (1997) Functional analysis: a fundamental empirical study for reverse engineering, benchmarking and redesign. In: Proceedings of the 9th ASME international conference on design theory and methodology, September 1997

Ookubo M, Koji Y, Sasajima M, Kitamura Y, Mizoguchi R (2007) Towards interoperability between functional taxonomies using an ontollogy-based mapping. In: Proceedings of the 16th international conference on engineering design (ICED '07), Paris, vol 154, pp 419-420

Pahl G, Beitz W (1996) Engineering design: a systematic approach. Springer, London

Rosenman MA, Gero JS (1998) Purpose and function in design: from the socio-cultural to the technophysical. Des Stud 19:161-186

Simons PM (1986) Categories and ways of being. Rep Philos 10:89-104

Simons PM (2005) Ingarden and the ontology of dependence. In: Chrudzimski (2005), pp 39-53

Stone RB, Wood K (2000) Development of a functional basis for design. J Mech Des 122(4):359-276

Stone RB, Wood KL, Crawford R (1998) A heuristic method to identify modules from a functional description of a product. In: Proceedings of DETC98, Atlanta

Szykman S, Sriram R, Racz J (1999) The representation of function in computer-based design. In: Proceedings of the 1999 ASME design engineering conference (11th international conference on design theory and methodology), paper No. DETC99/DTM-8742, Las Vegas, Nevada, September 1999

Thomasson AL (2005) Ingarden and the ontology of cultural objects. In: Chrudzimski (2005), pp 115-136

von Wachter D (2005) Roman ingarden's ontology: existential dependence, substances, ideas, and other things empiricists do not like. In: Chrudzimski (2005), pp 55-81 